\title{
Smoking-attributable cancer mortality in California, 1979-2005
}

\author{
David W Cowling, ${ }^{1}$ Juan Yang ${ }^{2}$
}

${ }^{1}$ California Department of Public Health, CDIC/California Tobacco Control Program, Sacramento, California, USA

${ }^{2}$ Sequoia Foundation, Richmond, California, USA

\section{Correspondence to}

David Cowling, California Department of Public Health, PO Box 997377, MS 7206, CDIC/California Tobacco Control Program, Sacramento, California 95899-7377, USA; david.cowling@cdph.ca.gov

Received 3 April 2009 Accepted 7 September 2009

\section{ABSTRACT}

Background The adult smoking prevalence has declined more in California than the rest of the US in the past 2 decades. Further, California has faster declines in cancer mortality, lung cancer incidence and heart disease mortality. However, no study has examined smoking-related cancer mortality between California and the rest of the US.

Methods The smoking-attributable cancer mortality rate (SACMR) from 1979 to 2005 in California and the rest of the US are calculated among men and women 35 years of age or older using the Joinpoint regression model to calculate the SACMR annual percentage change. The SACMR is the sum of the smoking-attributable death rates of 10 smoking-attributable cancers.

Results The SACMR has declined more in California $(25.7 \%)$ than the rest of the US $(8.9 \%)$ from 1979 to 2005. California men had a lower SACMR than the rest of the US over the entire study period, with the difference tripling from $7.4 \%$ in 1979 to $23.9 \%$ in 2005 . The difference of female SACMR between California and the rest of the US went from $17.9 \%$ higher in 1979 to $13.4 \%$ lower in 2005.

Conclusions California's SACMR decrease started 7 years earlier than the rest of the US (1984 vs 1991), and California experienced an accelerated decline of SACMR compared to the rest of the US overall and among men and women from 1979 to 2005. Although the SACMR started declining before the creation of the California Department of Public Health, California Tobacco Control Program, the SACMR rate of decline in California accelerated after the programme's inception.

\section{INTRODUCTION}

Previous studies show that trends in smokingattributable mortality can be a good reflection of the smoking prevalence change pattern over a long period of time. ${ }^{1-5}$ Smoking-attributable mortality has been used as a marker to determine and evaluate tobacco control efforts. ${ }^{6-8}$ California was the first state to initiate a statewide comprehensive tobacco control programme in 1989 that included social, regulatory and environmental strategies. ${ }^{9}$ This approach in California has led to a significantly lower and faster decline in adult smoking prevalence in California than in the rest of the US. ${ }^{10}$ The smoking prevalence among California adults has dropped by 46.5\%, from 25.8\% in 1984 to $13.8 \%$ in $2007 .{ }^{11}$ In comparison, the US prevalence based on the National Health Interview Survey (NHIS) has decreased approximately $38.6 \%$, from $32.1 \%$ in 1983 to $19.7 \%$ in $2007 .{ }^{12}$

Because smokers that smoke fewer cigarettes per day are at a lower risk of disease, ${ }^{13}$ especially for lung cancer or heart disease, on a population level a noticeable change in smoking-related diseases should be observable when cigarette consumption declines. Cigarette consumption has also decreased faster in California and is currently half the number of the rest of the US. ${ }^{11}$ Adult per capita cigarette consumption decreased by $75 \%$, from 160 in 1980 to 40 in 2006, whereas the rest of the US decreased by $55 \%$, from 183 in 1980 to 82 in $2006^{11}$

This change in population-level smoking behaviour over time has correlated with better health outcomes. Heart disease mortality has been shown to be decreasing faster in California than in the rest of the US, ${ }^{14}$ while lung cancer incidence and mortality have been shown to have peaked and are declining faster in California than the rest of the US. $^{15}$ Between 2001 and 2005, lung cancer incidence among women decreased in only one state: California. ${ }^{16}$ The male lung cancer death rate in California peaked first and is decreasing at such a rate that the death rate is approaching that of Utah. ${ }^{16}$ Although these long-term health outcomes are a lagging indicator of various tobacco control policies, which makes specific intervention attribution difficult, these lung cancer declines have been related to the California Department of Public Health, California Tobacco Control Program (CTCP). ${ }^{17}$

Smoking causes about $85 \%$ of the lung cancer cases. Lung cancer mortality is a specific measure of the smoking impact on health outcomes. ${ }^{16} 18$ Nine other cancers are also caused by smoking. ${ }^{18} 19$ Therefore, the total smoking impact on cancer mortality can be measured by the smoking-attributable death rate of the 10 cancers in total, even though these cancers have vastly different aetiologies, develop at different rates and are less attributable to smoking. Our goal was to simply examine the trends in smokingattributable cancer mortality from 1979 to 2005 in California and the rest of the US.

\section{METHODS \\ Study population}

To evaluate the smoking impact on cancer mortality change over time, this study compared the smoking-attributable cancer mortality rate (SACMR) change in California and the rest of the US from 1979 to 2005. We examined the SACMR of adults aged 35 years or older.

\section{Smoking status}

Smoking status data came from the NHIS from 1979 to 2005. Current smokers included current daily smokers or some day smokers who reported having smoked at least 100 cigarettes during their lifetime. Never smokers were defined as those who reported having smoked less than 100 cigarettes unlocked scheme, see http:// tobaccocontrol.bmj.com/site/ about/unlocked.xhtml. 
during their lifetime. Former smokers referred to those who smoked at least 100 cigarettes during their lifetime but did not smoke currently. Details about the survey methodology have been published elsewhere. ${ }^{20}$ The NHIS did not collect smoking data in the years 1981, 1982, 1984, 1986, 1989 and 1996. We applied the 'loess' method using $R^{21}$ to model smoking prevalence in those years and to smooth the prevalence trends. $R$ is an integrated suite of statistical software for data manipulation, calculation and graphical display.

\section{Cancer mortality}

A total of 10 types of smoking-related cancers were included to calculate the SACMR, including lip/oral cavity/pharynx, oesophagus, stomach, pancreas, larynx, trachea/lung/bronchus, cervix uteri (for women only), kidney/renal pelvis, urinary bladder and acute myeloid leukaemia. The age-adjusted death rates of each cancer for men and women aged 35 years or older came from the Surveillance, Epidemiology, and End Results (SEER) programme. ${ }^{22}$ We used the SEER*Stat software package $^{23}$ to retrieve annual death rates of the 10 cancers in California and the rest of the US during 1979-2005. The cancer death rates from the SEER programme were derived from death certificate data maintained by the National Center for Health Statistics. We standardised the cancer death rates in each calendar year to the 2000 US Census population for direct comparison over years between California and the rest of the US.

\section{Smoking-attributable fraction}

The smoking-attributable fraction (SAF) is the maximal proportion of cancer deaths causally linked to cigarette smoking. The calculation of the SAF for each cancer requires sex-specific current and former cigarette smoking prevalence and sex-specific $\mathrm{RR}$ of the 10 cancers in relation to smoking status. The formula (equation 1) for calculating the SAF, developed by the adult Smoking-Attributable Mortality, Morbidity, and Economic Costs (SAMMEC) software, ${ }^{24}$ was derived from attributable risk formulae to account for the different levels of exposure for current smokers and former smokers as indicated by separate prevalence rates and relative risk estimates:

$\mathrm{SAF}=\frac{\left(\mathrm{p}_{0}+\mathrm{p}_{1} \times \mathrm{RR}_{1}+\mathrm{p}_{2} \times \mathrm{RR}_{2}\right)-1}{\mathrm{p}_{0}+\mathrm{p}_{1} \times \mathrm{RR}_{1}+\mathrm{p}_{2} \times \mathrm{RR}_{2}}$

where $p_{0}$ is the percentage of never smokers (persons who have smoked $<100$ cigarettes), $p_{1}$ is the percentage of current smokers (persons who have smoked $\geq 100$ cigarettes and now smoke every day or some days), $\mathrm{p}_{2}$ is the percentage of former smokers (persons who have smoked $\geq 100$ cigarettes and do not currently smoke), $\mathrm{RR}_{1}$ is the relative risk for current smokers relative to never smokers, and $R_{2}$ is the relative risk for former smokers relative to never smokers.

The relative risks of the 10 cancers were estimated and provided by the American Cancer Society (ACS) based on data from ACS's Cancer Prevention Study II. ${ }^{25}$ The RRs were calculated as the ratio of cancer death rate for current or former smokers relative to cancer death rate for never smokers among adults aged 35 years or older.

Prevalence of current, former and never smokers came from the above-mentioned NHIS survey. Because the NHIS survey did not provide data to calculate smoking rates in California and the rest of the US separately, the national smoking rates were used to calculate the smoking-attributable fraction.

\section{SACMR}

We used methods similar to those described in the adult SAMMEC software ${ }^{24}$ to estimate the SACMR. This was the sum of smoking-attributable death rates due to the abovementioned 10 cancers. The smoking-attributable death rate was calculated by multiplying the death rate of a cancer by the estimated SAF of the cancer. Male and female SACMRs were calculated separately, and a simple average of the two was calculated to represent the overall population in California and the rest of the US.

\section{Annual percentage change}

To better compare the SACMR trend of California to that of the rest of the US during 1979-2005, we applied the Joinpoint regression model to identify the significant change points and to report the annual percentage change (APC) between the identified points. The Joinpoint regression interpreted changes over time more accurately and determined if those changes were statistically significant. We used the Joinpoint regression program V.3.3 $3^{26}$ to fit the Joinpoint regression models. The program took the SACMR trend data in 1979-2005 and fitted a series of straight lines to the SACMR on the log scale. The straight lines were connected together at the year of 'joinpoints'. Each joinpoint year denoted a statistically significant $(p \leq 0.05)$ change in trend. The tests of significance used the Monte Carlo permutation method to find the 'best fit' line for each time period defined by the joinpoint years. ${ }^{27}$ The program started with the minimum number of joinpoint (eg, 0 joinpoints, which is a straight line) and tested whether more joinpoints were statistically significant and must be added to the model (up to that maximum number). The program provided model fitting results and one graph for each joinpoint model, from the model with the minimum number of joinpoints to the model with maximum number of joinpoints. The program also marked a model with the optimum number of joinpoints, which we used as the final model to best describe the SACMR trends in California and the rest of the US during 1979-2005. In addition, the program provided the annual percentage change of SACMR and its $95 \%$ CI over each time period defined by the joinpoint years. ${ }^{28}$ The annual percentage change summarised the SACMR trend between two joinpoint years. More details of the Joinpoint Regression Program can be found at http://srab.cancer.gov/ joinpoint/. We compared the joinpoint years and the APC values of the SACMR during 1979-2005 between California and the rest of the US.

\section{RESULTS}

Due to the continuous smoking prevalence drop over the past 2 decades, ${ }^{23}$ the SACMR decreased in California and in the rest of the US as expected. Overall, the SACMR dropped $25.7 \%$ in California, from 126.2 per 100000 in 1979 to 93.8 in 2005, while the SACMR in the rest of the US dropped 8.9\%, from 129.4 per 100000 to 117.9 during the same period (table 1). The SACMR in California was only $2.5 \%$ lower than that in the rest of the US in 1979 , but was $20.4 \%$ lower than that in the rest of the US in 2005.

The SACMR increased in California and the rest of the US at the beginning of 1980s. SACMR started to decrease in 1984 in California, 7 years earlier than the rest of the US in which the decrease did not occur until 1991 (figure 1). The Joinpoint regression model indicated an accelerated decrease of SACMR in California since 1984 but a slower decrease in the rest of the US since 1991. The APC in California was $-1.1 \%$ (95\% CI $-1.5 \%$ to $-0.7 \%$ ) from 1984 to 1994, which accelerated to $-2.6 \%$ (95\% CI 
Table 1 Smoking-attributable cancer mortality rate (SACMR) and 95\% $\mathrm{Cl}$ among adults aged 35 years or older in California and the rest of the USA, 1979-2005

\begin{tabular}{|c|c|c|c|c|}
\hline \multirow[b]{2}{*}{ Year } & \multicolumn{2}{|c|}{ California } & \multicolumn{2}{|c|}{ Rest of the USA } \\
\hline & SACMR & $95 \% \mathrm{CI}$ & SACMR & $95 \% \mathrm{CI}$ \\
\hline 1979 & 126.2 & 125.4 to 126.9 & 129.4 & 129.2 to 129.7 \\
\hline 1980 & 128.5 & 127.7 to 129.3 & 131.9 & 131.7 to 132.2 \\
\hline 1981 & 129.9 & 129.1 to 130.7 & 132.4 & 132.1 to 132.6 \\
\hline 1982 & 131.9 & 131.1 to 132.7 & 134.5 & 134.2 to 134.7 \\
\hline 1983 & 131.1 & 130.3 to 131.8 & 135.4 & 135.2 to 135.7 \\
\hline 1984 & 133.2 & 132.5 to 134.0 & 136.7 & 136.4 to 136.9 \\
\hline 1985 & 131.7 & 131.0 to 132.4 & 137.2 & 137.0 to 137.4 \\
\hline 1986 & 129.6 & 128.9 to 130.2 & 138.1 & 137.8 to 138.3 \\
\hline 1987 & 130.2 & 129.5 to 130.9 & 139.3 & 139.0 to 139.5 \\
\hline 1988 & 130.7 & 130.1 to 131.4 & 139.7 & 139.5 to 140.0 \\
\hline 1989 & 129.1 & 128.5 to 129.8 & 141.1 & 140.9 to 141.4 \\
\hline 1990 & 128.5 & 127.9 to 129.1 & 142.5 & 142.3 to 142.7 \\
\hline 1991 & 127.0 & 126.4 to 127.6 & 142.2 & 141.9 to 142.4 \\
\hline 1992 & 123.2 & 122.6 to 123.8 & 140.9 & 140.7 to 141.1 \\
\hline 1993 & 123.4 & 122.8 to 123.9 & 140.5 & 140.3 to 140.7 \\
\hline 1994 & 122.2 & 121.7 to 122.8 & 138.3 & 138.1 to 138.5 \\
\hline 1995 & 120.2 & 119.6 to 120.7 & 137.0 & 136.8 to 137.2 \\
\hline 1996 & 116.3 & 115.8 to 116.9 & 135.4 & 135.2 to 135.6 \\
\hline 1997 & 115.4 & 114.9 to 115.9 & 133.5 & 133.3 to 133.7 \\
\hline 1998 & 110.7 & 110.2 to 111.2 & 132.3 & 132.1 to 132.5 \\
\hline 1999 & 109.5 & 109.1 to 110.0 & 127.7 & 127.6 to 127.9 \\
\hline 2000 & 106.0 & 105.6 to 106.4 & 127.8 & 127.7 to 128.0 \\
\hline 2001 & 106.4 & 105.9 to 106.8 & 125.9 & 125.7 to 126.1 \\
\hline 2002 & 102.8 & 102.4 to 103.2 & 124.2 & 124.1 to 124.4 \\
\hline 2003 & 98.7 & 98.3 to 99.1 & 121.8 & 121.7 to 122.0 \\
\hline 2004 & 95.3 & 94.9 to 95.7 & 119.6 & 119.5 to 119.8 \\
\hline 2005 & 93.8 & 93.4 to 94.2 & 117.9 & 117.7 to 118.0 \\
\hline
\end{tabular}

SACMR is presented as number of cases per 100000 . The included smoking attributable cancers are: lip, oral cavity, pharynx; oesophagus, stomach; pancreas; larynx; trachea, lung, bronchus; cervix uteri (for women only); kidney and renal pelvis; urinary bladder; and acute myeloid leukaemia. The age-adjusted cancer death rates in each calendar year were standardised to the 2000 US Census population.

$-2.8 \%$ to $-2.4 \%$ ) from 1994 to 2005 , while the APC in the rest of the US was $-1.8 \%$ (95\% CI $-1.9 \%$ to $-1.7 \%$ ) from 1991 to 2005 (table 2).

Over the entire time period, California men had a lower SACMR than the rest of the US, with the difference tripled from $7.4 \%$ in 1979 to $23.9 \%$ in 2005 (table 3). The SACMR of Californian men decreased continuously over the entire period, with an accelerated APC which increased more than four times, from $-0.9 \%(95 \%$ CI $-1.5 \%$ to $-0.2 \%)$ in $1979-1988$ to $-3.7 \%(95 \%$ $\mathrm{CI}-3.9 \%$ to $-3.5 \%)$ in $1988-2005$. Different from the monotonic decrease of the Californian male SACMR, the SACMR for the rest of US males did not decrease (APC $0.2 \%, 95 \%$ CI $0.0 \%$ to $0.4 \%$ during 1979-1991) until 1991 (APC -3.6\%, 95\% CI -3.7\% to $-3.5 \%$ during $1991-2005)$.

The female SACMR in California was $17.9 \%$ higher than the rest of the US in 1979. It changed to $13.4 \%$ lower than the rest of the US in 2005 due to an earlier and faster decline started in 1993. California and the rest of the US experienced an increase of the female SACMR in the 1980s and early 1990s before the start of a decrease. The APC in California was $2.2 \%(95 \%$ CI $1.8 \%$ to $2.7 \%$ ) in $1979-1984$, slowed down to $0.7 \%$ in $1984-1993(95 \%$ CI $0.4 \%$ to $0.9 \%$ ), then started to decrease significantly with APC accelerating from $-0.9 \%(95 \%$ CI $-1.2 \%$ to $-0.7 \%)$ in $1993-2001$ to $-1.9 \%$ (95\% CI $-2.5 \%$ to $-1.4 \%)$ in $2001-2005$. Similar to California, the APC of SACMR increase in the rest of the US was 1.8 (95\% CI $1.7 \%$ to $1.9 \%$ ) in 1979-1991, and also slowed down to $0.7 \%$ (95\% CI $0.2 \%$ to $1.1 \%$ ) in $1991-1996$. However, the SACMR in the rest of the US levelled off in
1996-2002 (APC -0.1\%, 95\% CI $-0.4 \%$ to $0.2 \%$ ), while California was experiencing the SACMR decline. The rest of the US did not experience the SACMR decline until 2002 (APC - 1.0\%, $95 \%$ CI $-1.6 \%$ to $0.4 \%$ in $2002-2005$ ).

\section{DISCUSSION}

The aggregate measure of tobacco cancer mortality burden in California and the rest of the US strengthen the previous findings that smoking-related health outcomes are currently different in California than the rest of the US. Although some health outcomes could be influenced by tobacco control measures in the short term, the SACMR is a longer-term measure with the complete underlying effects of changes in smoking behaviour playing out over decades. Nevertheless, noticeable effects could be expected to be observable in the first decade. ${ }^{17}$ The SACMR is a complex function of a variety of factors, including initiation and cessation-related cohort effects and survival rates for the smoking-related cancers.

After the latest change point, the SACMR for men in California and the rest of the US are on similar percentage declines. The primary difference in the trends are that the California was already declining prior to the change point and that the latest change point occurred in 1988 compared to 1991 in the rest of the US. This has resulted in a continuous offset in the SACMR of about 36 per 100000 or $23 \%$ since 1991.

For women, the SACMR in California stopped rising as fast and peaked earlier in California in comparison to the rest of the US. From 2001 to 2005, the California SACMR for women doubled the previous rate of decline from 1993 to 2001. Although not following the exact trend pattern, the rest of the US's SACMR trend has followed the California trend with a delay of roughly 10 years.

The difference and earlier peak in SACMR between California and the rest of the US may partially be related to California's smoking behaviour changes occurring earlier in California than the rest of the US. ${ }^{10} 2930$ The accelerated declines of smoking prevalence and smoking consumption in California occurred in the late 1980s. They are partially a result of California's Proposition 99 in 1988, which raised the excise tax on a pack of cigarettes by $\$ 0.25$ and established CTCP. ${ }^{31}$

This study has several limitations. The cancer death rate derived from death certificates has reporting inaccuracy, although the reporting accuracy of cancers is better than other diseases. $^{32} 33$ The change of death cause coding from the International Classification Of Disease (ICD) from ICD-9 to ICD-10 in 1999 may have caused discontinuing mortality trends over years. ${ }^{34} 35$ SAFs are treated as known quantities in the analysis although the relative risks and smoking prevalence used to calculate them are based on estimates. Due to a lack of comparable data of smoking prevalence between California and the rest of the US, SAFs were calculated using the national smoking prevalence from the NHIS instead of California specific data. Because smoking-attributable cancer deaths play out over a long period of time ${ }^{36}$ and SACMRs are derived from current year smoking prevalence, reported SACMR may have been underestimated, given that smoking rates in previous years were much higher and may have biased the SACMR trend to certain extent. The cancer mortality caused by secondhand smoking was not included in the SACMR computation. The APC of SACMR was statistically tested between time periods within California and the rest of the US but not between the two. Due to the limitations of the Joinpoint regression program, we could not set up the same set of points for a direct comparison between California and the rest of the US. Potential 
Figure 1 Smoking-attributable cancer mortality rate (SACMR) among adults aged 35 years or older in California and the result of the USA, 1979-2005.
Smoking-attributable cancer mortality rate (per 100,000)

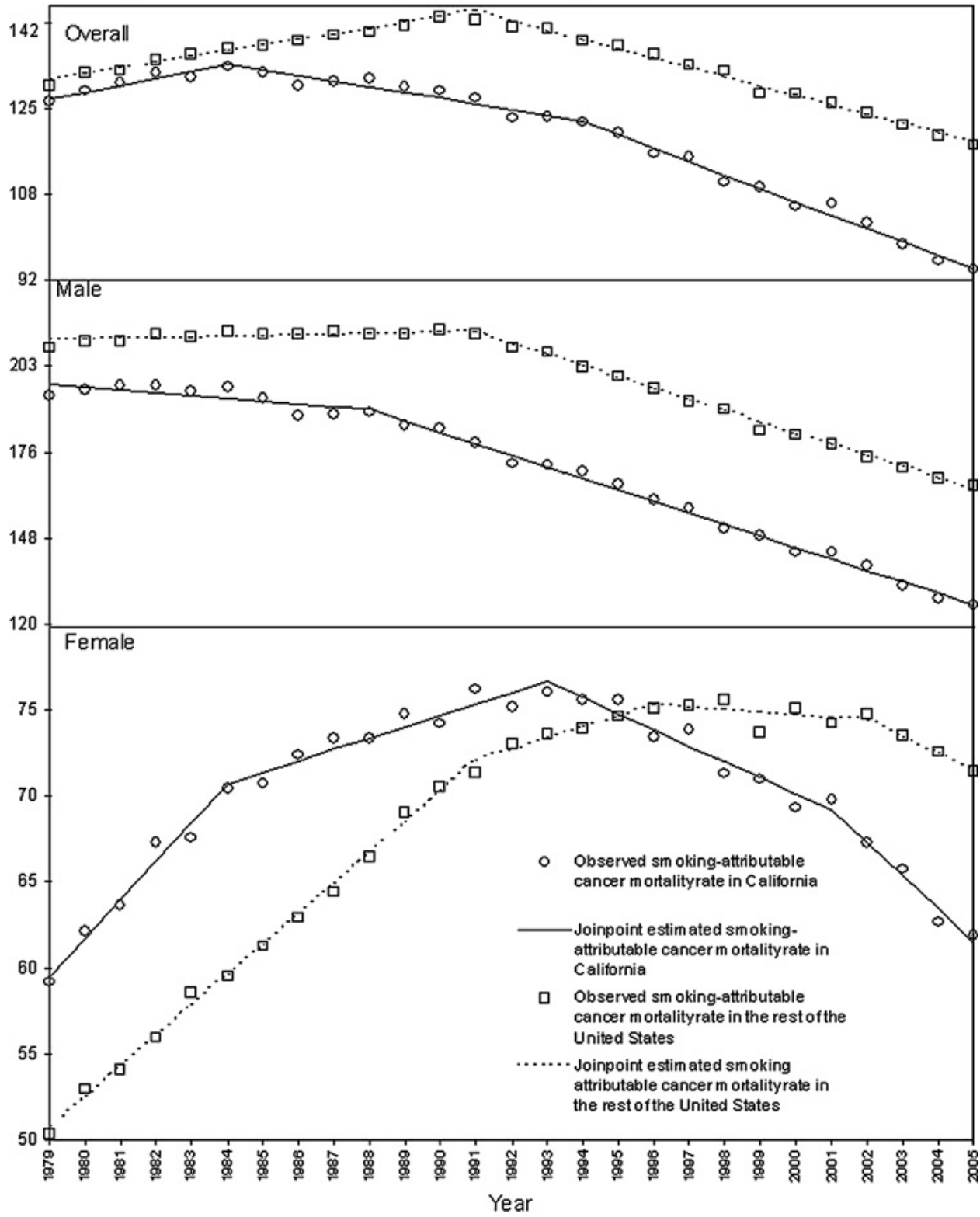

confounding factors, such as socioeconomic status, which could have influenced the smoking exposure, cancer mortality and relative risk of smoking in relation to cancer mortality, were not tested and controlled. Also, this study does not draw a direct correlation between CTCP or the changes in smoking behaviour and the outcome (smoking-attributable cancer mortality).

Lastly, the large Latino and Asian populations in California with their lower smoking prevalence, particularly among

Table 2 Annual percentage change and $95 \% \mathrm{Cl}$ of smoking-attributable cancer mortality rate (SACMR) among adults aged 35 years or older in California and the rest of the USA: Joinpoint regression results

\begin{tabular}{|c|c|c|c|c|c|c|c|c|}
\hline & \multicolumn{4}{|l|}{ California } & \multicolumn{4}{|c|}{ Rest of the USA } \\
\hline & Joinpoint & Years (range) & APC $(\%)$ & $95 \% \mathrm{Cl}$ & Joinpoint & Years (range) & APC $(\%)$ & $\mathbf{9 5 \%} \mathrm{Cl}$ \\
\hline \multirow[t]{2}{*}{ Overall } & 1984 & 1979-1984 & 1.3 & 0.2 to 2.4 & 1991 & 1979-1991 & 1.1 & 1.0 to 1.2 \\
\hline & & $1994-2005$ & -2.6 & -2.8 to -2.4 & & & & \\
\hline \multirow[t]{2}{*}{ Male } & 1988 & $1979-1988$ & -0.9 & -1.5 to -0.2 & 1991 & $1979-1991$ & 0.2 & 0.0 to 0.4 \\
\hline & & $1988-2005$ & -3.7 & -3.9 to -3.5 & & $1991-2005$ & -3.6 & -3.7 to -3.5 \\
\hline \multirow{2}{*}{ Female } & 2001 & $1993-2001$ & -0.9 & -1.2 to -0.7 & 2002 & $1996-2002$ & -0.1 & -0.4 to 0.2 \\
\hline & & $2001-2005$ & -1.9 & -2.5 to -1.4 & & $2002-2005$ & -1.0 & -1.6 to 0.4 \\
\hline
\end{tabular}

Bold numbers are statistically different from 0 at the $5 \%$ level.

APC, annual percentage change. 
Table 3 Smoking-attributable cancer mortality rate (SACMR) and 95\% $\mathrm{Cl}$ among men and women aged 35 years or older in California and the rest of the USA, 1979-2005

\begin{tabular}{|c|c|c|c|c|c|c|c|c|}
\hline \multirow[b]{3}{*}{ Year } & \multicolumn{4}{|c|}{ California } & \multicolumn{4}{|c|}{ Rest of the USA } \\
\hline & \multicolumn{2}{|c|}{ Male } & \multicolumn{2}{|l|}{ Female } & \multicolumn{2}{|c|}{ Male } & \multicolumn{2}{|l|}{ Female } \\
\hline & SACMR & $95 \% \mathrm{CI}$ & SACMR & $95 \% \mathrm{Cl}$ & SACMR & $95 \% \mathrm{Cl}$ & SACMR & $95 \% \mathrm{Cl}$ \\
\hline 1979 & 193.6 & 192.1 to 195.2 & 58.7 & 58.4 to 58.9 & 209.1 & 208.5 to 209.6 & 49.8 & 49.7 to 49.9 \\
\hline 1980 & 195.4 & 193.9 to 196.9 & 61.6 & 61.4 to 61.9 & 211.4 & 210.9 to 211.9 & 52.4 & 52.4 to 52.5 \\
\hline 1981 & 196.7 & 195.1 to 198.2 & 63.2 & 62.9 to 63.4 & 211.2 & 210.7 to 211.7 & 53.5 & 53.4 to 53.6 \\
\hline 1982 & 197.1 & 195.6 to 198.6 & 66.7 & 66.5 to 67.0 & 213.5 & 213.0 to 214.0 & 55.4 & 55.4 to 55.5 \\
\hline 1983 & 195.1 & 193.7 to 196.6 & 67.0 & 66.8 to 67.3 & 212.8 & 212.3 to 213.3 & 58.0 & 58.0 to 58.1 \\
\hline 1985 & 193.1 & 191.8 to 194.5 & 70.2 & 69.9 to 70.5 & 213.6 & 213.2 to 214.1 & 60.7 & 60.7 to 60.8 \\
\hline 1986 & 187.2 & 185.9 to 188.6 & 71.9 & 71.6 to 72.2 & 213.8 & 213.3 to 214.2 & 62.4 & 62.3 to 62.5 \\
\hline 1987 & 187.6 & 186.3 to 188.9 & 72.8 & 72.5 to 73.1 & 214.6 & 214.2 to 215.1 & 63.9 & 63.8 to 64.0 \\
\hline 1988 & 188.6 & 187.3 to 189.9 & 72.9 & 72.6 to 73.2 & 213.5 & 213.1 to 214.0 & 65.9 & 65.8 to 66.0 \\
\hline 1989 & 184.0 & 182.7 to 185.2 & 74.3 & 74.0 to 74.5 & 213.8 & 213.3 to 214.2 & 68.5 & 68.4 to 68.6 \\
\hline 1990 & 183.3 & 182.1 to 184.6 & 73.7 & 73.4 to 74.0 & 215.0 & 214.5 to 215.4 & 70.0 & 69.9 to 70.1 \\
\hline 1995 & 165.2 & 164.2 to 166.3 & 75.1 & 74.8 to 75.4 & 199.9 & 199.5 to 200.2 & 74.1 & 74.0 to 74.2 \\
\hline 1996 & 159.8 & 158.8 to 160.8 & 72.9 & 72.6 to 73.2 & 196.2 & 195.8 to 196.5 & 74.6 & 74.5 to 74.7 \\
\hline 1997 & 157.5 & 156.5 to 158.5 & 73.3 & 73.0 to 73.6 & 192.2 & 191.8 to 192.5 & 74.8 & 74.7 to 74.9 \\
\hline 1998 & 150.6 & 149.7 to 151.5 & 70.8 & 70.5 to 71.0 & 189.5 & 189.1 to 189.8 & 75.1 & 75.0 to 75.2 \\
\hline 1999 & 148.6 & 147.7 to 149.5 & 70.5 & 70.3 to 70.7 & 182.3 & 182.0 to 182.6 & 73.2 & 73.1 to 73.3 \\
\hline 2000 & 143.2 & 142.3 to 144.1 & 68.8 & 68.6 to 69.0 & 181.1 & 180.8 to 181.4 & 74.6 & 74.5 to 74.7 \\
\hline 2001 & 143.4 & 142.6 to 144.3 & 69.3 & 69.1 to 69.6 & 178.2 & 177.8 to 178.5 & 73.7 & 73.6 to 73.8 \\
\hline 2002 & 138.9 & 138.1 to 139.7 & 66.8 & 66.5 to 67.0 & 174.2 & 173.9 to 174.5 & 74.2 & 74.2 to 74.3 \\
\hline 2003 & 132.2 & 131.4 to 132.9 & 65.2 & 65.0 to 65.5 & 170.6 & 170.3 to 170.9 & 73.0 & 73.0 to 73.1 \\
\hline 2004 & 128.5 & 127.7 to 129.2 & 62.1 & 61.9 to 62.3 & 167.2 & 166.9 to 167.5 & 72.1 & 72.0 to 72.1 \\
\hline 2005 & 126.2 & 125.5 to 126.9 & 61.4 & 61.2 to 61.6 & 164.9 & 164.6 to 165.1 & 70.9 & 70.8 to 71.0 \\
\hline
\end{tabular}

SACMR is presented as number of cases per 100000 . The included smoking attributable cancers are: lip, oral cavity, pharynx; oesophagus, stomach; pancreas; larynx; trachea, lung, bronchus; cervix uteri (for women only); kidney and renal pelvis; urinary bladder; and acute myeloid leukaemia. The age-adjusted cancer death rates in each calendar year were standardised to the 2000 US Census population.

\section{What this paper adds}

A number of studies have shown that California has seen a decline in smoking related health outcomes, including lung cancer incidence and mortality and heart disease mortality, in comparison to the rest of the nation. This is the first study that compares the smoking-attributable cancer mortality (SACMR) change between California and the rest of the United States from 1979 to 2005. The study reveals that the SACMR decease in California started 7 years earlier than the rest of the United States. Additionally, this decline in California is faster than the rest of the United States among men, women and combined.

women, may have contributed to the lower SACMR in California compared to the rest of the US. Hispanics and Asian/ Pacific Islanders have a lower incidence of lung cancer than nonHispanic whites. They might also have different susceptibilities to the smoking-attributable cancers. ${ }^{37} 38$ However, we have seen similar declines in lung cancers between African-Americans and non-Hispanic whites, but a slower decline among Hispanics and Asian/Pacific Islanders from 1988 to $2005 .{ }^{39}$ Additionally, the observed decline among Hispanics and Asian/Pacific Islanders was not different between California and the rest of the US during 1990-2005. ${ }^{40}$ Consequently, the faster decline of overall SACMR in California is unlikely to be due to the different racial/ ethnic mix in California.
Although the ecological correlations that we observe do not prove a causal relationship between any particular tobacco control intervention and the decrease in cancer death rate, the enlarging discrepancy between California and the rest of the US in recent years suggests a result due to the long-term and ongoing tobacco control programme in California.

Tobacco control efforts in California have taken hold and led to a social norm change that has led to a noticeable difference in smoking behaviours in California. In turn, these changes appear to have led to differences in heart disease, lung cancer and smokingattributable cancer mortality. These results are an optimistic sign that the rest of the US will also start benefiting from national and the sustained state tobacco control efforts in other states.

Acknowledgements The authors we would like to thank Dave Burns, Byron Kennedy and Sandy Kwong for providing feedback on earlier drafts of this paper.

Competing interests None declared.

Contributors Both authors contributed to the conception and design, acquisition of data or analysis and interpretation of data; drafting the article or revising it critically for important intellectual content; and final approval of the version published.

Provenance and peer review Not commissioned; externally peer reviewed.

\section{REFERENCES}

1. U.S. Department of Health and Human Services. Reducing the health consequences of smoking: 25 years of progress. A report from Surgeon General. Rockville, MD: U.S. Department of Health and Human Services, Public Health Service, Centers for Disease Control, Center for Chronic Disease Prevention and Health Promotion, Office on Smoking and Health, 1989 DHHS Publication No. (CDC) 89-8411. 
2. Armour BS, Woollery T, Malarcher A, et al. Annual smoking-attributable mortality, years of potential life lost, and productivity losses-United States, 1997-2001. Morb Mortal Wkly Rep 2005;54:625-28.

3. CDC. State-specific smoking-attributable mortality and years of potential life lost United States, 2000-2004. MMWR 2009;58:29-33.

4. CDC. Smoking- attributable mortality, years of potential life lost, and productivity losses - United States, 2000-2004. MMWR 2008;57:1226-8.

5. CDC. Cigarette smoking among adults - United States, 2007. MMWR 2008;57:1221-6.

6. Nelson DE, Kirkendall RS, Lawton RL, et al. Surveillance for smoking-attributable mortality and years of potential life lost, by state-United States, 1990. Morb Mortal Wkly Rep 1994;43:1-8.

7. World Health Organization (WHO). Framework convention on tobacco control, 2003. http://www.who.int/gb/fctc.

8. Starr G, Rogers T, Schooley M, et al. Key outcome indicators for evaluating comprehensive tobacco control programs. Atlanta, GA: Centers for Disease Control and Prevention, 2005

9. Bal D, Kizer $\mathrm{K}$, Felton $\mathrm{P}$, et al. Reducing tobacco consumption in California: development of a statewide anti-tobacco use campaign. JAMA 1990;264:1570-74.

10. Siegel M, Mowery PD, Pechacek TP, et al. Trends in adult cigarette smoking in California compared with the rest of the United States, 1978-1994. Am J Public Health 2000;90:372-9

11. California Tobacco Control Update. 2008. 20 years of tobacco control in California. California Department of Public Health, California Tobacco Control Program, 2009.

12. NHIS. 2007. http://www.cdc.gov/nchs/data/series/sr 10/sr10 240.pdf

13. U.S. Department of Health and Human Services. The health benefits of smoking cessation. U.S. Department of Health and Human Services, Public Heath Service, Centers for Disease Control, Center for Chronic Disease Prevention and Health Promotion, Office on Smoking and Health, 1990 DHHS Publication No. (CDC) 90-8416.

14. Fichtenberg CM, Glantz SA. Association of the California tobacco control program with declines in cigarette consumption and mortality from heart disease. $N$ Engl $J$ Med 2000;343:1772-7.

15. Centers for Disease Control and Prevention. Declines in lung cancer ratesCalifornia, 1988-1997. MMWR Morb Mortal Wkly Rep 2000;49:1066-9.

16. Jemal A, Cokkinides VE, Shafey 0 , et al. Lung cancer trends in young adults: an early indicator of progress in tobacco control (United States). Cancer Causes Control 2003; 14:579-85.

17. Barnoya J, Glantz S. Association of the California tobacco control program with declines in lung cancer incidence. Cancer Causes Control 2004;15:689-95.

18. U.S. Department of Health and Human Services. The health consequences of smoking: a report of the surgeon general. Atlanta, Georgia: U.S. Department of Health and Human Services, Centers for Disease Control and Prevention, National Center for Chronic Disease Prevention and Health Promotion, Office on Smoking and Health, 2004.

19. IARC Working Group on the Evaluation of Carcinogenic Risks to Humans. Tobacco smoke and involuntary smoking. World Health Organisation, International Agency for Research on Cancer, Lyon, France: 2004

20. NHIS description. http://www.cdc.gov/nchs/about/major/nhis/hisdesc.htm.

21. The R Foundation for Statistical Computing. Version 2.2.0.

22. SEER details. http://seer.cancer.gov.
23. Surveillance, Epidemiology, and End Results (SEER) Program (http://www.seer. cancer.gov) SEER*Stat Database: Mortality-All COD, Public-Use With State, Tota U.S. (1969-2002), National Cancer Institute, DCCPS, Surveillance Research Program, Cancer Statistics Branch, released April 2005. Underlying mortality data provided by NCHS (http://www.cdc.gov/nchs).

24. Centers for Disease Control and Prevention. Smoking-attributable mortality, morbidity, and economic costs (SAMMEC): adult SAMMEC and maternal and child health (MCH) SAMMEC software. 2004. http://www.cdc.gov/tobacco/sammec.

25. Thun MJ, Day-Lally C, Myers DG, et al. Trends in tobacco smoking and mortality from cigarette use in cancer prevention studies I (1959 through 1965) and II (1982 through 1988). In: Changes in cigarette-related disease risks and their implication for prevention and control. Smoking and tobacco control monograph 8. Bethesda, MD: U.S. Department of Health and Human Services, Public Health Service, National Institutes of Health, National Cancer Institute, 1997: 305-82

26. National Cancer Institute. Joinpoint regression program, version 3.3. 2008. Statistical Research and Applications Branch, National Cancer Institute. http://srab. cancer.gov/joinpoint/

27. Kim HJ, Fay MP, Feuer EJ, et al. Permutation tests for joinpoint regression with applications to cancer rates. Stat Med 2000:19:335-51 (correction: 2001:20:655).

28. Jemal A, Clegg LX, Ward E, et al. Annual report to the nation on the status of cancer, 1975-2001, with a special feature regarding survival. Cancer 2004;101:3-27.

29. Gilpin EA, Emery SL, Farkas AJ, et al. The California tobacco control program: a decade of progress, results from the california tobacco surveys, 1990-1998. La Jolla, CA: University of California, San Diego, 2001.

30. Pierce JP, Gilpin EA, Emery SL, et al. Has the California tobacco control program reduced smoking? JAMA 1998:280:893-9.

31. Bal DG, Lloyd JC, Roeseler A, et al. California as a model. J Clin Oncol 2001; 19(18 Suppl):69S-73S

32. Rosenberg H. Improving cause-of-death statistics. Am J Public Health 1989;79:563-64

33. Kirby RS. The coding of underlying cause of death from fetal death certificates: Issues and policy considerations. Am J Public Health 1993;83:1088-91.

34. Jemal A, Ward E, Anderson RN, et al. Influence of rules from the tenth revision of the international classification of diseases on U.S. cancer mortality trends. J Natl Cancer Inst 2003;84:1727-8.

35. American Lung Association. Trends in lung cancer morbidity and mortality, 2005 http://www.lungusa.org/att/cf/\%7B7A8D42C2-FCCA-4604-8ADE-7F5D5E762256\% 7D/lc1.pdf.

36. Fellows JL, Trosclair A, Adams EK. Annual smoking-attributable mortality, years of potential life lost, and economic costs-United States, 1995-1999. MMWR Morb Mortal Wkly Rep 2002;51:300-3

37. Haiman CA, Stram DO, Wilkens LR, et al. Ethnic and racial differences in the smoking-related risk of lung cancer. NEJM 2006;354:333-42.

38. Burns PB, Swanson GM. Risk of urinary bladder cancer among blacks and whites: the role of cigarette use and occupation. Cancer Causes Control 1991;2:371-9

39. California Cancer Registry. http://www.cancer-rates.info/ca/, 2009

40. State Cancer Profiles. http://statecancerprofiles.cancer.gov/, 2009. 